\title{
Social effects of digital pornography
}

\author{
Muhammad Firman Aji Saputra ${ }^{1, *}$, Sherly Allsa Siregar ${ }^{2}$, Zahra Nabila Izdihar ${ }^{3}$ \\ Universitas Negeri Malang, Malang, Indonesia \\ ${ }^{1}$ firman.asbn@gmail.com *; ${ }^{2}$ sherlyallsasiregar@gmail.com; ${ }^{3}$ zahra.informatics@ gmail.com \\ * corresponding author
}

\begin{abstract}
ARTICLE INFO ABSTRACT
Article history

Received October 10, 2017

Revised October 31, 2017

Accepted November 20, 2017

Keywords

Technology

Pornography

Cyberporn

Internet

Emerging technology will provide benefits for users. Especially with the presence of the internet will make technology more perfect. On the one hand, technology and the internet provide benefits, on the other hand can also give a negative impact for users, one of which is the rise of pornographic content on the internet or often called cyberporn. With the internet, pornography can be obtained easily. That is because the producers of pornographic content think that the internet is the most optimal marketing medium. The presence of pornography has occurred pros and cons in various countries. In Indonesia, it is strictly prohibited because it can damage the morale of the next generation of the nation. In addition, pornography is something very addictive to humans that will eventually happen in various things. In fact, porn addiction is more severe addictive substance addiction than psychotropic. Some efforts that can be done to minimize the pornography deal either by the government of Indonesia, family, or other related parties are making laws that regulate pornography, blocking pornographic sites, providing early childhood sex education, and the role of parents in child supervision.
\end{abstract}

This is an open access article under the CC-BY-SA license.

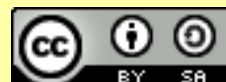

\section{Introduction}

Technology will continue to evolve over time. Technology is no longer a secondary or tertiary need, but has become a primary need that must be owned by every individual. The current information technology, making almost all regions can feel the benefits of information technology. With information technology, every individual is made easier to get the information he wants.

The development of information technology is also not spared from the role of the internet that has been present in this world. The Internet has been considered to be the greatest discovery, where everyone can get information from around the world using internet. This integrated information technology and Internet makes the world only in the grip now.

Meanwhile, the development of technology can also have a negative impact on its users. As a consequence, the changes that occur in the community due to advances in technology and the Internet cannot be avoided anymore. One effect is that each individual is free to communicate anything unconstrained by the limits of conventional values and norms, even to issues that may have been taboo to be openly discussed, pornographic issues.

Pornography is increasingly accessible in this era. As a result, pornographic content is easy to handle even in the hands of minors. Two recent reports, from the American Psychological Association on Hypersexualized Girls and the National Campaign to Prevent Teen Pregnancy report that pornographic content has reached the phone's childrens [1].

In Indonesia, pornography is indeed widespread, not only teenagers who have access but also children. Pornography has invited various controversies both pros and cons. Many things related to pornography, from the matter of history, culture, politics, technology, to the economy. Similarly, 
pornography has given rise to a diverse stream of thought. Therefore things about the crime of pornography are an interesting topic to be discussed in this journal.

\section{Literature Review}

\subsection{Information Technology}

Information Technology (IT) is a term relating to computer and communication systems. Information technology includes everything related to processes, manipulation, and information management [2]. Information technology can also be interpreted as an integrated tool for capturing data, processing and sending information.

Information technology itself is made on the basis of science that can help various human's jobs. Utilization of information technology can helping humans, but has some negative effects so it takes wisdom for its users.

Information technology has a very important role in society because it can affect the attitudes, values and behaviors, and establish conditions for identity, and existence [3]. In information technology, humans have a role as makers, carriers, and receivers of information. There are several points of view related to the use of information technology on sexuality, here are 6 areas of information technology utilization on sexuality [4]:

\section{1) Pornography}

With the information technology, users can access both commercial and non-commercial pornography online. In addition they can also produce, distribute and discuss pornographic-related content as they want.

\section{2) Sex Shop}

Internet users can obtain information about sexual aids. Internet users can also purchase those items via online. Online sex shops usually concentrate on marketing non-digital products such as vibrators, condoms, aphrodisiacs, lingerie, and erotic magazines.

\section{3) Sex Work}

The Internet can be used for offline work sex marketing (such as advertising for prostitution) and on the other hand allows for new forms of online sex work (e.g. live sex via webcam, video calls and so on). In contrast to pornography that consisting of sexual texts, images, or video that have been produced previously, sex work includes real time interpersonal contact between client and sex worker.

\section{4) Sex Education}

The Internet offers much needed information, this information can be used to alter sexual awareness, attitudes, and behaviors, and also promote healthy sex. Internet users can search and access information they find useful and reliable from various sources.

\section{5) Sex Contacts}

There are 2 types of sex contacts: first, using information and communication technology intermediaries (online sex, eg via video call) and second, meet offline. Information technology can be used as an intermediary to connect with each other. The difference with sex work is sex contacts not for commercial purposes.

\section{6) Sexual Subculture}

People with non-mainstream sexual orientation or preference especially those who have difficulty finding similar minded people can easily find people who share their own orientation and preferences on the Internet. Sexual subculture can be easily searched for when connected to the internet.

\subsection{Pornografi}

Pornography is derived from the Greek word (porne and graphein). In Indonesia pornography is defined as deliberate deeds associated with drawings, sketches, illustrations, photographs, writings, sounds, sounds, motion pictures, animations, cartoons, conversations, gestures, or other forms of communication through various forms of communication media or in advance shows public that contain elements of sexual abuse or exploitation. Thus, anyone who presents pornographic content in any form, is automatically involved in the act of pornography. Pornographic content is usually disseminated through four media, namely: 
1) Print Media

It prints women's drawings in sensual, transparent, open-ended, or open-totality with seductive pose with nasty papers like photography, books, posters, calendars, cards, magazines, novels, comics, other.

\section{2) Image Media (Visual)}

In the visual media is the same as the print media displaying pornographic images or paintings of women with open bodies. Such as, painting, graffiti, cover design, interior, and so on.

\section{3) Audio Media audio}

Media that presents lethargic voices with interactive dialogue and broadcasts, dirty talk, sighs, tempting screams, filthy poems, and so on. This sound media is usually obtained from radio, cassette, phone, MP3, and others.

\section{4) Audio-visual Image}

This media is a media that is very vulnerable and dangerous to the morality of the nation, because of the sophisticated technology in presenting pornographic movements that move and sound, which is very liked and easily imitated teenagers and people who are immoral and irresponsible. Voice media images are commonly obtained from TV, video, VCD, widescreen movies, and others.

\subsection{Cyberporn}

Cyberporn is a pornographic content that is digitally loaded. Cyberporn is a term usually given on digital images, and the site that contains pornography [5]. One of the information technology that is often used to access pornographic content is internet. Pornographic content spread over the Internet spreads faster because it is easy to find pornographic links on search engines. Cyberporn is not only accessible to adults but also underage children and is often misused by irresponsible people so, cyberporn is included in Cybercrime or crime in Information technology.

\section{Pornography Damages the Brain}

Pornography affects several human hormones so that pornography can affect brain performance, the following will be discussed about hormones that are affected by pornography and its relation to the concentration of the human brain:

\subsection{Dopamine}

Dopamine (DA) acts as a major neurotransmitter in the brain. This hormone causes a sensation like satisfied, and happy. Dopamine pathways are connected to three other keys that form a circuit called a reward system, the three keys are the amygdala (regulating positive and negative emotions), the hippocampus (processing and retrieval of long-term memory), and the frontal cortex (coordinating and defining behaviors) [6].

When dopamine in the brain increases it will activate the rewards system. Rewards system is what triggers dependence on pornography. If the rewards pathway in the brain is active then when people addicted to pornography stop to see things related to pornography will feel the symptoms of anxiety, difficulty concentrating, and insomnia.

\subsection{Noradreanline}

Noradrenaline is involved in various psychological functions and behaviors. One of the most important is its role in "attention" and "passion". This hormone also regulates anxiety and memory of negative perceptions [7]. This hormone causes a person who is addicted to pornography will imagine things that are not appropriate.

\subsection{Serotonin}

Make a person feel comfortable when serotonin hormone out. Serotonin dysfunction can lead to obsessive compulsive disorder, aggression, eating disorders, and schizophrenia and migraine headaches [7]. Serotonin arises from something that provides a sense of "calm" in the body such as eating, sleeping and other activities that are considered "comfortable", including pornography because some people think pornography is entertaining that describes the effect of "calming". 


\subsection{Oksitosin}

The hormone is secreted by the pituitary gland (located at the base of the brain) and is classified as a peptide containing 9 amino acids. These nine small amino acid peptides are involved in various physiological and pathological functions such as sexual activity, penile erection, ejaculation, pregnancy, uterine contractions, milk expulsion, maternal behavior, social bonding, stress and so on [8]. Someone will love something that makes hormone oxytocin release. This causes a pornographic addict to have an inner bond with pornography so that the person always want to see pornography. Because of pornography is addictive, it can cause various changes in the brain. Some stages of addiction that cause brain changes include:

1) Sensitization (cue-reactivity \& cravings)

Brain circuits that engage in motivation and reward become very sensitive to memories or cues associated with addictive behaviors. This leads to an increase desire [9]. People who have been addicted to pornography (e.g. looking at pornographic images or videos), will feel not satisfied with the "pornography" thing that he usually consume and then the person will experience increased needs become more wild or more distorted.

2) Desensitization (decreased reward sensitivity \& tolerance)

It involves long-term chemical and structural changes that make individuals less sensitive to pleasure. Desensitization often manifests as tolerance, i.e. the need for high or greater dose stimulation to achieve the same response. At this stage, material that is taboo, and immoral, will become commonplace. Consumers of pornography even become less sensitive to sexual violence.

3) Dysfunctional prefrontal circuits

Distractions in Prefrontal Circuits in addiction not only make a person use illegal drugs but also cause misbehavior caused by addiction [10].

4) Malfunctional stress system

Something that can make addictions can damage the stress system because chronic addiction can induce some changes in the stress system of the brain, and also affect the circulation of stress hormones (cortisol and adrenaline).

\section{Information Technology and Pornography}

The existence of the internet provides the ease of accessing pornographic content causing pornography to be higher in its spread. The existence of pornography is out of control [11]. Research in the United States has shown that $66 \%$ of men and $41 \%$ of women consume pornography every month [12]. This number is increasing due to the presence of pornographic content on the internet [13]. It proves technological developments also affect the spread of pornography.

Describing sexual explicitly and potentially stimulating activities on the Internet are usually in the form of photos, videos clips and movies, comics, and text. Online pornography is available on the website either for free or for a fee. In addition to erotica/soft-core and hardcore pornography, illegal pornography is the third form of explicit sexual content available online (albeit to a lesser extent).

Online child pornography is very difficult to find for non-sophisticated users, because child pornography is illegal in most developed countries. For this reason, Child pornography is almost always sold or exchanged in a closed area and usually sold for a considerable price. On the other side, animal pornography is relatively easy to find for free because animal pornography is considered legal in some countries [4]. With the information technology, especially the internet then the user is possible to access any information including pornography, form of pornography that can be accessed also diverse with different costs as well. The pornography in digital form on the Internet makes it easy for users to get pornographic content and then store it in their own devices even with a sizeable file size.

\section{The Effect of Pornography}

\subsection{Effect of Pornography}

Pornography can have certain effects on humans. The end result of to the use of pornography varies greatly, especially when it comes to sexual results. There are two points of view of the effects of pornography are: 
1) Positive Impact

Many people report that consumption of pornography is associated with an increase in sexual life, increased sexual knowledge, and a more positive and permissive attitude about sexuality. In some other studies also mentioned that in heterosexual young men, the consumption of pornography does not seem to be related to desire, erection, or difficulty of orgasm [14]. Pornography can also be used for couples to get a new model or way of making love so as to enhance the couple's sexuality life. This positive effect applies only to adults where they already have adequate education on sex.

\section{2) Negative Impact}

Use of pornography is associated with sexual effects such as compulsive sexual behavior, dependence on pornography, and risky or perverse sexual behavior [14]. The negative effect of pornography is when a person becomes dependent on pornography. Pornographic addicts use pornography in the same way as alcoholics use alcohol until they numb and rise from their painful lives [15]. Pornography is something very addictive to humans that will eventually happen in various things. In fact, the number of published studies is a more severe addiction to pornography than addictive addiction and psychotropic substances. Pornography can also increase men's aggressive behavior towards women [16]. In addition, because of the pornography can also cause the rampant exploitation of children for sex in order to gain profits.

Pornography has positive and negative effects, depending on how a person use of the pornography whether someone uses it to get positive things like education about sex and satisfaction for a spouse or they use it for negative things like sex trafficking, sex crimes, etc.

\subsection{Cyberporn in Children Under Age and Adolescence}

With the existence of information technology, pornography is more easily accessible by all circles including children and adolescents. This is a separate issue related to cyberporn, which children and adolescents who are not old enough and not worth to have sex related education can access easily.

The problem of cyberporn in underage children is a very important thing, which in the era is the development of the brain so that pornography will be more to damage the mindset and behavior of children under age than adults. Underage child exposure to pornography is associated longitudinally with decreased academic achievement in boys, the possibility of increased early sexual initiation, and other sexual behaviors [17]. In addition to causing addiction, pornography is also progressive, as people become dissatisfied with the pornography they see, so that those who are addicted to pornography will look for more and more severely. Therefore, it is not surprising that child pornography becomes extremely vicious [18].

Minors do not have enough education about sex and therefore are more vulnerable to negative effects of pornography than adults. Many adults worry that "pornographic content" will cause trauma for minors.

The problem of cyberporn in adolescence is the age at which the level of curiosity is very high, one of them against things related to sex. However, in adolescence, they are usually still embarrassed to ask their parents about sex so they can find out directly through the internet that can lead to a misconception about sex education, so that students can get caught up in aberrant sexual behavior. In adolescence, they usually get information about sex with friends, by discussing together, reading sex material books or doing extreme ways to experiment with masturbation, scratching or even worse is having sex. It will later have a negative impact, rape and others.

\section{Cyberporn Prevention Effort}

Indonesia has made various efforts to minimize the effects of cyberporn that will occur. Efforts to prevent the impact of cyberporn done by various parties, either by the government, the family, as well as other relevant parties. This is some precautions that can be done:

- Making the Cyberporn Act. This effort is one of the efforts made by the government. The goal is that cyberporn can be controlled, at least will provide a sense of security for internet users and put pressure on the elements who are not responsible for pornographic content on the internet. The form of realization is Law no. 44 of 2008 on pornography that has been made by the government. 
- Blocking Pornographic sites. This is another way the government makes pornographic websites not easily accessible from the internet. This is considered a powerful way to minimize pornographic content on the internet. However, because of the large number of pornographic websites that exist on the internet, it will make the government trouble and takes a long time.

- Film Censorship. The Government of Indonesia requires every film producer or advertisement to censor the pornographic stuff in its products. Later, the Indonesian censorship (Lembaga sensor Indonesia) agency will provide a recommendation decision that the impression may be published for public.

- Supervise Underage Children. Providing supervision of children is a task of parents. Supervision aims to prevent children from falling into forbidden acts. Always communicating with children is also one of the ways that parents can make it so that children are always under surveillance. If you have to introduce gadgets or other technological devices to minors, then parents should keep an eye on them.

- Providing Education Related Sex. Provision of education about sex is very necessary especially when someone is stepping on adolescence. Adolescence is often known as the time to seek identity or called the identity of the ego (ego identity). This happens because adolescence is a transitional period between the life span of children and adult life span.

\section{Conclusion}

Technology has made the spread of pornographic content even easier. Pornographic content more easily to get from various countries with various genres, either free or paid. Manufacturers of pornography often use the internet to market its products either paid or free. Of course, this raises concerns for internet users in the world including in Indonesia. As discussed in this journal, pornography can have a detrimental effect on the audience, one of which is the worst affected brain performance which is the brain will experience several stages of change such as, sensitization, desensitization, Dysfunctional prefrontal circuits, and malfunction stress system. However, the pros and cons of pornography still occur. For the pros, consumption of pornography is associated with an increase in sexual life, increased sexual knowledge, and a more positive and permissive attitude about sexuality. Pornography can also be used for couples to get a new model or way of making love so as to enhance the couple's sexuality life. This positive effect applies only to adults which they already have adequate education on sex. As for the counter, assume that the use of pornography is associated with adverse sexual effects such as compulsive sexual behavior, dependence on pornography, and risky or distorted sexual behavior. Pornography is something that is very addictive for humans that will eventually affect in various things. In fact, pornography addiction is more severe than addictive substance addiction and psychotropic. Pornography can also increase men's aggressive behavior towards women. In addition, because of the pornography can also lead to the rampant exploitation of children for sex in order to gain profits. In Indonesia, pornography is strictly prohibited. Pornography is considered to damage the morale of the next generation of the nation. Some efforts that can be done to minimize the existence of pornography either done by the government of Indonesia, family, as well as other related parties are making laws that regulate pornography, blocking pornographic sites, providing early childhood sex education, and the role of parents in supervising their children.

\section{References}

[1] P. F. Fagan, "The Effects of Pornography on Individuals, Marriage, Family, and Community," Marriage \& Religion Research Institute. pp. 1-26, 2009.

[2] V. Venkatesh, M. G. Morris, G. B. Davis, and F. D. Davis, "User Acceptance of Information Technology: Toward a Unified View," J. Chem. Inf. Model., vol. 27, no. 3, pp. 425-478, 2013.

[3] I. Karlsson, "Ethics and Information and Communication Technology," IFAC Proc. Vol., vol. 36, no. 22, pp. $75-80,2003$.

[4] N. M. Döring, "Computers in Human Behavior The Internet' s impact on sexuality : A critical review of 15 years of research," Comput. Human Behav., vol. 25, no. 5, pp. 1089-1101, 2009.

[5] R. H. Potter and L. a Potter, "the Internet, Cyberporn, and Sexual Exploitation of Children: Media Moral Panics and Urban Myths for Middle-Class Parents?," Sex. Cult., vol. 5, no. 3, pp. 31-48, 2001. 
[6] T. Love, C. Laier, M. Brand, L. Hatch, and R. Hajela, "Neuroscience of Internet Pornography Addiction: A Review and Update," Behav. Sci. J., vol. 5, no. 1, pp. 388-433, 2015.

[7] A. Uppala, "International Journal of Recent Scientific Research," Int. J. Recent Sci. Res., vol. 6, no. 10, pp. 6632-6636, 2015.

[8] N. Magon and S. Kalra, "The orgasmic history of oxytocin: Love, lust, and labor," Indian J. Endocrinol. Metab., vol. 25, no. Suppl3, pp. 156-161, 2011.

[9] T. E. Robinson and K. C. Berridge, "The incentive sensitization theory of addiction : some current issues," Philos. Trans. R. Soc. London B Biol. Sci., vol. 363, no. 1507, pp. 3137-3146, 2008.

[10]R. Z. Goldstein and N. D. Volkow, "Dysfunction of the prefrontal cortex in addiction: neuroimaging findings and clinical implications," Nat Rev Neurosci, vol. 12, no. 11, pp. 652-669, 2012.

[11]D. Zillmann and J. Bryant, "Pornography and sexual callousness, and the trivialization of rape," $J$. Commun., vol. 32, no. 4, pp. 10-21, 1982.

[12]S. Kühn and J. Gallinat, "Brain structure and functional connectivity associated with pornography consumption: the brain on porn," JAMA psychiatry, vol. 71, no. 7, pp. 827-834, 2014.

[13]J. Wolak, K. Mitchell, and D. Finkelhor, "Unwanted and wanted exposure to online pornography in a national sample of youth Internet users," Pediatrics, vol. 119, no. 2, pp. 247-257, 2007.

[14] S. Blais-Lecours, M. P. Vaillancourt-Morel, S. Sabourin, and N. Godbout, "Cyberpornography: Time use, perceived addiction, sexual functioning, and sexual satisfaction," Cyberpsychology, Behav. Soc. Netw., vol. 19, no. 11, pp. 649-655, 2016.

[15]R. P. Cox and M. D. Howard, "Utilization of EMDR in the treatment of sexual addiction: A case study," Sex. Addict. Compulsivity, vol. 14, no. 1, pp. 1-20, 2007.

[16]D. O. Yang and G. Youn, "Effects of exposure to pornography on male aggressive behavioral tendencies," Open Psychol. J., vol. 5, no. 1, 2012.

[17]E. F. Rothman, J. Paruk, A. Espensen, J. R. Temple, and K. Adams, "A qualitative study of what US parents say and do when their young children see pornography," Acad. Pediatr., vol. 17, no. 8, pp. 844849, 2017.

[18] B. H. Schell, M. V. Martin, P. C. Hung, and L. Rueda, "Cyber child pornography: A review paper of the social and legal issues and remedies-and a proposed technological solution," Aggress. Violent Behav., vol. 12, no. 1, pp. 45-63, 2007. 